\title{
Correction to: Novel metagenome-derived ornithine lipids identified by functional screening for biosurfactants
}

\author{
Wesley Williams ${ }^{1}$ (I) $\cdot$ Lovemore Kunorozva $^{1} \cdot$ Iris Klaiber $^{2} \cdot$ Marius Henkel $^{3} \cdot$ Jens Pfannstiel $^{2} \cdot$ Johannes Günther $^{4}$. \\ Jürgen Conrad ${ }^{5} \cdot$ Leonardo J. Van Zyl $^{1} \cdot$ Rudolf Hausmann $^{3} \cdot$ Anita Burger $^{1} \cdot$ Marla Trindade $^{1}$
}

Published online: 4 May 2019

(C) Springer-Verlag GmbH Germany, part of Springer Nature 2019

\section{Correction to: Applied Microbiology and Biotechnology https://doi.org/10.1007/s00253-019-09768-1}

The published online version contains mistake in the author list. Two authors mistakenly omitted from the authors list are Johannes Günther and Jürgen Conrad.

Publisher's note Springer Nature remains neutral with regard to jurisdictional claims in published maps and institutional affiliations.

The online version of the original article can be found at https://doi.org/ 10.1007/s00253-019-09768-1

Marla Trindade

ituffin@uwc.ac.za

1 Institute for Microbial Biotechnology and Metagenomics, Faculty of Natural Sciences, University of the Western Cape, Cape Town 7535, South Africa

2 Core Facility Hohenheim, Mass Spectrometry Unit, University of Hohenheim, 70593 Stuttgart, Germany

3 Institute of Food Science and Biotechnology, Section Bioprocess Engineering, University of Hohenheim, 70599 Stuttgart, Germany

4 Core Facility Hohenheim, Spectroscopy Unit, University of Hohenheim, 70593 Stuttgart, Germany

5 Institute of Chemistry, Department of Bioorganic Chemistry, University of Hohenheim, 70599 Stuttgart, Germany 